\title{
Redeployment of Athletic Trainers During a Pandemic
}

\author{
James Caiola, MS, LAT, ATC*
}

* MedStar Health, Washington, DC

\section{Full Citation}

Caiola J. Redeployment of Athletic Trainers During a Pandemic. Clin Pract Athl Train. $2021 ; 4(1): 61$. https://doi.org/10.31622/2021/0004.1.8.

Presented at the 4rd Annual Athletic Trainers in the Physician Practice Society Meeting and Conference, February 26-27, 2021.

\section{ABSTRACT}

Before COVID-19 was recognized as a global pandemic involving the United States of America in March of 2020, MedStar Health employed 40 Athletic Trainers (ATs) in multiple settings. While ATs worked in the traditional setting at 17 high schools, 2 universities, and with 2 professional teams in the Baltimore, MD and Washington, DC area, they also have been used in nontraditional ways. They are used in the physician practice setting to manage clinic flow, evaluate patients and present to the physician, provide pre- and post-surgical patient education, and being an overall patient point of contact in a busy clinic. They have also been used in nontraditional ways with work as coordinators for research projects, helping to organize information and write grant proposals. Community Liaisons (CL), an additional AT function in our system, are also a crucial and beneficial member of the MedStar Health Sports Medicine Staff. There are $5 \mathrm{CL}$ 's in the system ranging from working in locations such as the national headquarters of US Lacrosse and the Saint James Sports Complex, a commercial multipurpose sports training site, and on the frontline overseeing partnerships such as the Maryland Black Bears and Area Boys and Girls Clubs.

It has not been uncommon for employees within medical systems to be furloughed due to shifting clinic needs. No employees of MedStar Sports Medicine have been laid off as a result of redeployment, they have been utilized in different areas. In these times, system ATs have exemplified their versatility by being redeployed to call centers, facilitating patient contact with COVID test results, working Urgent Cares shifts to do Preop testing and help with patient flow in busy centers, and becoming contact tracers. This presentation will explore how MedStar Health Sports Medicine responded to COVID-19.

\section{Correspondence}

James Caiola, 1120 20th St NW Suite 1 15, Washington, DC 20036

Email: James.m.caiola@medstar.net 